\title{
Review
}

\section{Filarial hydrocele: a neglected condition of a neglected tropical disease}

\author{
Kenneth Bentum Otabil ${ }^{1,2}$, Seth Boateng Tenkorang ${ }^{2}$ \\ ${ }^{1}$ Department of community Medicine and Health, Anglican University College of Technology, Nkoranza, BA, Ghana \\ 2 Department of Medical Research, Emmavick Eye Clinic, Sunyani, Ghana
}

\begin{abstract}
Filarial hydrocele is the most common chronic manifestation of lymphatic filariasis (LF) and poses a major public health burden to several filarial endemic countries. This review highlights the socio-economic impact of the disease, the role of the immune system in hydrocele development, current diagnostic approaches, and the control and management of filarial hydrocele. In the quest to facilitate the global effort to eliminate filarial hydrocele as a neglected tropical disease, a more comprehensive understanding of the mechanisms underlying the pathogenesis and development of the condition is important. In general, success has been achieved using annual treatment with ivermectin, but much remains to be done, particularly with late-stage infected individuals where surgery remains the only option. Studies have successfully demonstrated that inhibition of embryogenesis in adult female worms occurs after weeks of tetracycline treatment. Even more intriguing was the observation that the Wolbachia endosymbionts potently induce proinflammatory cytokines such as tumor necrosis factors (TNFs) and vascular endothelial growth factors (VEGFs), which are crucial for the development of filarial hydrocele. Furthermore, reports from human studies show that doxycycline treatment significantly ameliorates filarial hydrocele and markedly reverses early-stage filarial hydrocele. However, with the enormous challenges that face LF elimination such as global funding, logistics, civil wars, and drug resistance, a more relentless and collective approach from local governments as well as other stakeholders is needed to accelerate the fight against filarial hydrocele if the goal to eliminate it by 2020 is be to achieved.
\end{abstract}

Key words: hydrocele; filariasis; endemic; proinflammatory; Wolbachia.

J Infect Dev Ctries 2015; 9(5):456-462. doi:10.3855/jidc.5346

(Received 27 May 2014 - Accepted 14 January 2015)

Copyright (C) 2015 Otabil et al. This is an open-access article distributed under the Creative Commons Attribution License, which permits unrestricted use, distribution, and reproduction in any medium, provided the original work is properly cited.

\section{Introduction}

Lymphatic filariasis (LF) is one of the oldest and most debilitating diseases known to humanity [1]. The disease is caused by the filarial worms Wuchereria bancrofti, Brugia malayi and B. timori. W. bancrofti accounts for $90 \%$ of the infections. The worms are transmitted by mosquitoes and are endemic in more than 80 countries in tropical and sub-tropical areas of Africa, Asia, the Pacific, the Middle East, and the Americas [2]. More than 1.4 billion people, or onefifth of the world's population, most of whom are the world's poorest, are at risk [3]. Infection with $W$. bancrofti is usually acquired in childhood, but the painful and profoundly disfiguring visible manifestations of the disease such as hydrocele and elephantiasis occur later in life [4].

Filarial hydroceles are the most common chronic manifestation of LF [5] and afflict an estimated 27 million men worldwide [6]. Hydroceles result from the gradual accumulation of fluid in the tunica vaginalis of the scrotal sac and may be accompanied by thickening of the spermatic cord and changes in the scrotal skin and subcutaneous tissue [7] When left unattended, filarial hydroceles may lead to other urogenital complications, including lymph scrotum, a urogenital condition characterized by the presence of lymphatic vesicles on the surface of the scrotal skin that can easily rupture, giving rise to drainage of the whitish secretion typical of the disease. This secretion can then serve as an excellent culturing medium that favors repeated bacterial infections. These repeated bacterial infections can trigger the progression of the condition to acute inflammation of the scrotum and penis, elephantiasis of the scrotum, and inguinal adenitis [8]. Despite the fact that many males in endemic regions are infected, much remains to be established about the factors that drive filarial hydrocele development. Indeed, genetics of infected subjects could be a crucial factor. Other factors, such as co-infection, age, gender, and ethnic background, could also be driving forces that need to be validated further. 


\section{The social impact of disease on individuals and productivity}

Filarial hydroceles can have significant, and often negative, social impacts [7,9-11]. The degree of social disability varies among cultural settings, but the extent of stigmatization appears to be directly correlated with the severity of visible disease $[12,13]$. Gyapong et al. [14] suggested that the physical and psychological burden borne by men has a negative impact on their marriage and employment prospects. The extent of male sexual disability as a result of LF has not been extensively studied, but investigators believe that there is a significant silent burden [1,15]. Gyapong et al. [14] found that hydroceles had a significant impact on young men, particularly at a time when they were struggling to establish their sexual identity and their capacity to be reliable economic providers. However, unwillingness of men to admit to sexual dysfunction may shroud the real extent of this issue [11].

Affected individuals often avoid seeking treatment for fear of drawing attention to their condition $[13,16]$. Meanwhile, failure to treat the disease results in recurrent acute febrile attacks and progressive damage to the lymphatic system. Without access to simple hygiene practices, infected subjects are unable to prevent further progression of the outwardly visible complications of LF [17]. As the disease progresses, both labor productivity and sexual reproductive potential are increasingly hampered [11].

\section{Immunology of hydrocele development}

The events that lead to the development of chronic pathologies in lymphatic filariasis are not fully understood, but the immune responses of the human host to the parasites are believed to play a significant role in determining pathological manifestations such as hydroceles in infected individuals [18-22].

The lymphatic vascular system plays a critical role in immune surveillance, tissue fluid homeostasis, and fat absorption [23,24]. Perturbations in the maintenance and function of the lymphatic system can lead to a variety of pathological disorders, including lymphatic dilation and lymphedema $[23,25,26]$.

Recent studies on the molecular mechanisms controlling the lymphatic vessels have shown that vascular endothelial growth factors $\mathrm{C}$ (VEGF-C) and VEGF-D specifically control lymphangiogenesis in humans [27,28]. The expression of VEGF-C has also been shown to be upregulated by proinflammatory cytokines such as interleukin (IL)-1 $\beta$ and tumor necrosis factor (TNF), suggesting that proinflammatory cytokines could affect the lymphatic vessels via VEGF-C [22,29].

Taylor et al. [30] have shown in animal models that Wolbachia-derived molecules from Brugia spp. also induced proinflammatory cytokines, including TNF and IL-1B. Soluble extracts of Brugia and Onchocerca volvulus adult and microfilarial worms were also found to stimulate human peripheral mononuclear cells in vitro, resulting in the production of TNF, IL-1, granulocyte-macrophage colonystimulating factor (GM-CSF), and IL-10 [31,32]. This stimulation was not achieved using extracts from Acanthocheilonema viteae, a filarial species naturally devoid of Wolbachia, and, importantly, with $O$. volvulus extracts from patients who had been treated with doxycycline to deplete Wolbachia from the worms [30].

Thus, it was concluded that in those filarial species that contain these endosymbionts, Wolbachia are the major stimulating principle for proinflammatory cytokines such as TNF. From this, it can be further hypothesized that exposure of host cells to Wolbachia from worms (either from dying adult worms or incoming L3/4 larvae, or from the proportion of degenerating embryos that are constantly released) may induce the production of lymphangiogenic factors such as VEGF-C by endothelial cells in LF patients [22].

\section{Diagnosis of filarial hydroceles: the challenges}

Definite diagnosis of filarial hydroceles requires parasitological techniques to demonstrate the causal organisms. Microfilariae may be found in the blood, hydrocele fluid or, occasionally, in another body fluid. These fluids can be examined microscopically, either directly or, for greater sensitivity, after concentration of the parasites by the passage of fluid through a polycarbonate cylindrical filter (pore size, $5 \mu \mathrm{m}$ ) or by the centrifugation of fluid fixed in $2 \%$ formalin (Knott's concentration technique) or $2 \%$ formalin/ $10 \%$ Teepol [33]. Indeed, most filarial hydrocele patients, especially at the advanced stages, are amicrofilaremic, and this previously made diagnosis challenging. However, with the development of immunochromotographic test cards, this challenge has been overcome.

DNA-based techniques have been developed to diagnose and differentiate filarial parasites in humans, animal reservoir hosts, and mosquito vectors [34]. The techniques include DNA hybridization, polymerase chain reaction (PCR) amplification using specific 
primers (including Ssp I repeat, $\mathrm{pWb} 12$ repeat, $\mathrm{pWb}$ 35 repeat, and LDR repeat for $W$. bancrofti and Hha I repeat, glutathione peroxidase gene, mitochondrial DNA for B. malayi), and universal primers, multiplexPCR, PCR-restriction fragment length polymorphism (PCR-RFLP), PCR-enzyme linked immunosorbent assay (PCR-ELISA), as well as quantitative PCR. These techniques, however, need at least one microfilaria in the volume of blood used for DNA extraction, and therefore are not more sensitive than microscopic blood examination for microfilariae. They are, however, important tools for xenomonitoring in lymphatic filariasis [34-36].

A major step in the diagnosis of LF was made almost two decades ago, with the observation of what was described by Amaral et al. [37] as filarial dance signs (FDS). FDS were described as peculiar, randomappearing movements of objects inside a vessel-like structure. There are varying opinions on whether the echogenic particles represent adult filarial worms [38] or microfilaria, the larval form of filarial worms [39]. The general consensus, however, is that these objects are motile adult worms within dilated lymphatics, which may be visualized in the lymphatics of the spermatic cord in up to $80 \%$ of infected men [40-42].

Currently, the etiology of the so-called filarial dance signs is being debated. Adejolu and Sidhu [42] recently demonstrated that the sonographic appearance described as the filarial dance is not characteristic of filariasis but occurs even in non-endemic areas as a manifestation of epididymis obstruction. They suggest that the oscillating particles seen on sonography are not necessarily adult worms or microfilariae, but may be a manifestation of a complex pathophysiologic process common to men with epididymal obstruction and men infected with filariasis.

Their finding is supported by Shyamkumar et al. [39], who remarked that the moving particles could not represent adult worms because they are significantly smaller than adult worms. Further, some patients with filarial hydrocele (diagnosed by ultrasonography) do not have detectable microfilaria and circulating filarial antigens (Og4C3) in their blood [42-44]. This apparent discrepancy in ultrasonographic and biochemical/microbiological markers has been explained as resulting from the fact that ultrasonography is more sensitive in the diagnosis of filariasis than detection of either microfilaria or the circulating filarial antigen in the blood, especially when the microfilaria density is low $[42,45]$.

In the face of these conundrums, the World Health Organization (WHO) has made some recommendations to aid in diagnosis of filarial hydroceles. It is recommended that since an estimated $69 \%$ of all hydroceles are filarial in origin and the prevalence of hydroceles in non-endemic areas is considerably low, all hydroceles in $W$. bancroftiendemic areas are to be considered to be caused by filarial worms, unless otherwise proven [4]. Other causes of hydroceles are imbalance in fluid secretion and absorption, lymphatic filariasis, injury, radiation, retroperitoneal fibrosis, other infections and neoplasms [46].

\section{Treatment and management: successes and challenges}

The Global Programme for Elimination of Lymphatic Filariasis (GPELF) has two main goals: to interrupt transmission using microfilaricides given in mass drug administration (MDA) programs, and to reduce morbidity associated with chronic pathology including filarial hydrocele [3].

\section{Interrupting transmission of lymphatic filariasis}

The first goal of the GPELF has been pursued through the instrumentality of the MDA programs using ivermectin, albendazole, and diethylcarbamazine (DEC) [3]. MDA programs in endemic countries are considered to be more cost effective than properly diagnosing and treating infected individuals [2]. The low-side-effect profile of drugs and the pledge by two pharmaceutical companies to provide them free of charge, as long as necessary, makes the MDA a good elimination strategy [2].

Ivermectin is regarded as a pure microfilaricide, which kills nearly all microfilariae. However, several studies have demonstrated that ivermectin has no macrofilaricidal effect, although there are indications that it reduces fertility of the adult worms [47-49]. Some macrofilaricidal effect might occur though, if ivermectin is combined with the broad-spectrum albendazole [50]. Despite ivermectin's remarkable effect against microfilariae, a suboptimal response has been recently reported in Asubende area of Ghana [51].

In addition to ivermectin, DEC has a potent microfilaricidal effect as well as $50 \%$ macrofilaricidal activity [2,52-54]. The combination of DEC and albendazole has macrofilaricidal effects of between $56 \%$ and $87 \%$ [54]. However, in Africa, DEC cannot be used due to co-endemicity of lymphatic filariasis and onchocerciasis; the rapid killing of $O$. volvulus 
worms results in the development of severe adverse events.

Successes of the MDA regimes as reported by several independent investigators include reductions in microfilareaemia, antigenemia, and transmission rates [55-62] after years of administration of the MDA drugs. The results from these studies indicate that it is indeed possible to eliminate lymphatic filariasis and its attendant debilitating chronic pathologies, including filarial hydroceles.

\section{Management of morbidity: hydrocele}

Currently, the mainstay of filarial hydrocele management is hydrocelectomy because the current MDA drugs such as DEC or ivermectin, usually given with albendazole, have no effect on the adult worms and subsequently no ameliorative effect on filarial hydroceles $[2,4]$. This is because the chronic clinical manifestations of lymphatic filariasis such as hydroceles are initiated by activities of adult worms [63].

Adult worms cause mechanical blockage of the lymphatic vessels, eliciting several immune reactions, which culminates in dilation of scrotal lymphatics and attendant drainage of fluids into the scrotal sac. This is unlike the case of onchocerciasis (a closely related disease), where the baby worms are the initiators of pathogenesis. Meanwhile, hydrocelectomies are expensive and invasive, and relapse may occur even after a successful surgery; this is not easily welcomed by many individuals in rural settings where the infection rate is usually high.

A promising development in the management of morbidity is the discovery of the ability of some tetracyclines, especially doxycycline, to kill adult worms. Hoerauf et al. [64], in a study using Litomosoides sigmodontis, discovered that tetracycline therapy eliminated Wolbachia, the bacterial endosymbionts in adult worms and resulted in filarial growth retardation and infertility. Later, a pilot study with doxycycline administered at $200 \mathrm{mg}$ for six weeks depleted Wolbachia, sustained amicrofilaremia for a long time, and resulted in $80 \%$ disappearance of worm nests from scrotal areas of infected men examined by ultrasonography [65]. Other similar studies have also demonstrated similar activity with doxycycline [66]. Anti-wolbachial chemotherapy with doxycycline appears to have a higher macrofilaricidal effect (80\%) than does DEC, which showed 30\%-40\% worm nest disappearance, a finding that was interpreted as $30 \%-40 \%$ macrofilaricidal effect [50]. Indeed, anti-wolbachia drugs are known to have less severe adverse effects and demonstrable ameliorative outcomes in individuals with clinical pathology [22] compared to all standard anti-filarial treatments.

\section{Going forward: the challenges}

Despite 50 years of research into filariasis control, many questions still remain unanswered. Doxycycline is among the registered drugs mostly available and affordable in most endemic regions, which makes it safe to use without much supervision. Nevertheless, the possible risk of resistance among the population must be carefully considered. The use of doxycycline in the treatment of filarial hydrocele is still being investigated as an alternative method of treatment for individuals living with lymphatic pathology in endemic communities [22,41].

Furthermore, there are logistical challenges with regard to the use of doxycycline in filarial hydrocele patients especially on a large scale. These include the currently long regime of drug administration (200 mg of doxycycline daily for six weeks), which may discourage compliance and increase the occurrence of adverse events. Other challenges include the fact that to date, no study has achieved a $100 \%$ clearance of adult worms and the contra-indication of doxycycline in pregnant women and in children under nine years of age [66]. In spite of these challenges, individual patients with filarial hydrocele can benefit from doxycycline, which has been shown to ameliorate filarial hydrocele $[22,44]$, especially in the early stages of the pathology.

The exploration of antibiotics for treating filariasis is far from exhausted. The principle of drug synergism can be explored by combining two or more drugs in an effort to reduce treatment time and increase macrofilaricidal effect. Other antibiotics and chemicals should also be tried for their efficacy against the adult worms in lymphatic filariasis. For instance, following these field observational reports, it will be helpful if other alternative drugs, such as rifampicin, could be administered to children who cannot be given tetracyclines.

\section{Conclusions}

Although filarial hydrocele is an important pathology of lymphatic filariasis, its burden has largely been underestimated. The disease hampers economic productivity and presents fertility-related issues in most developing countries. Given that most cases of hydrocele go unreported for fear of victimization and stigmatization, there is a need to strengthen the current existing program of elimination 
and to campaign for more global support. Although the advent of recent molecular approaches has improved diagnosis approaches, there is still room for improvement. It is clear that the combination of surgery and treatment seems plausible, but the cost of surgery alone poses another layer of challenge. The introduction of anti-wolbachial therapy has provided a promising lead and should be pursued. Besides its macrofilaricidal potentials, anti-wolbachial therapy also leads to the amelioration of chronic filarial pathologies such as hydrocele and lymphedema. Additionally, the incorporation of more educational awareness in endemic community health programs could help infected individuals to report early to health facilities for quick medical attention.

In conclusion, the present review provides a current view of the treatment options, diagnostic approaches, and disease burden of filarial hydrocele, which will be helpful to governments in endemic regions as well as to several workers in the field of filarial biology.

\section{References}

1. World Health Organization (2010) Action against worms, July issue. Available: www.who.int/entity/neglected_diseases/preventive_chemothe rapy/Newsletter14_En.pdf. Accessed 16 July 2011.

2. Fernando SD, Rodrigo C, Rajapakse S (2011) Current Evidence on the Use of Antifilarial Agents in the Management of Bancroftian Filariasis. J Trop Med 1155: 75941.

3. World Health Organization (2013) Lymphatic filariasis. Available:

http://www.who.int/mediacentre/factsheets/fs 102/en/.

Accessed 26 December 2013.

4. World Health Organization (1992) Lymphatic filariasis: the disease and its control. Fifth report of the WHO expert committee on filariasis. Available: http://apps.who.int/iris/handle/10665/39309. Accessed 10 February, 2014.

5. Eigege A, Richards FO, Jr. Blaney DD, Miri ES, Gontor I, Ogah G, Umaru J, Jinadu MY, Mathai W, Amadiegwu S, Hopkins DR (2003) Rapid assessment for lymphatic filariasis in central Nigeria: a comparison of the immunochromatographic card test and hydrocele rates in an area of high endemicity. Am J Trop Med Hyg 68: 643-646.

6. World Health Organization (2008) The Global Burden of Disease: $2004 \quad$ Update. Available: http://www.who.int/healthinfo/global_burden_disease/2004_r eport_update/en/. Accessed 1 August 2011.

7. World Health Organization, Global Programme for the Elimination of Lymphatic Filariasis (2002) Surgical approaches to the urogenital manifestations of lymphatic filariasis. Available: http://whqlibdoc.who.int/hq/2002/WHO_CDS_CPE_CEE_20 02.33.pdf .Accessed 22May 2010.
8. Richens J (2004) Genital manifestations of tropical diseases. Sex Transm Infect 80: 12-17. doi: 10.1136/sti.2003.004093.

9. Remme JHF, Raadt P, Godal T (1993) The burden of tropical disease. Med J Aust 158: 465.

10. Bandyopadhyay L (1996) Lymphatic filariasis and the women of India. Soc Sci Med 42: 1401-1410.

11. Wynd S, Melrose WD, Durrheim DN, Carron J, Gyapong M (2007) Understanding the community impact of lymphatic filariasis: a review of the socio-cultural literature. Bull World Health Organ 85: 493-498.

12. Evans DB, Gelband H, Vlassoff C (1993) Social and economic factors and the control of lymphatic filariasis: a review. Acta Trop 53: 1-26.

13. Mujinja PGM, Gasarasi DB, Premji ZG, Nguma J (1997) Social and economic impact of lymphatic filariasis in Rufiji district, Southeast Tanzania. In: Lymphatic filariasis research and control in Africa. Report on a workshop held in Tanga, Tanzania. Tanzania: Danish Bilharziasis Laboratory, Denmark \& National Institute for Medical Research.

14. Gyapong M, Gyapong J, Weiss M, Tanner M (2000) The burden of hydrocele on men in Northern Ghana. Acta Trop 77: 287-294.

15. Dreyer G, Noroes J, Addiss D (1997) The silent burden of sexual disability associated with lymphatic filariasis. Acta Trop 63: 57-60.

16. Rauyajin O, Kamthornwachara B, Yablo P (1995) Sociocultural and behavioural aspects of mosquito-borne lymphatic filariasis in Thailand: a qualitative analysis. Soc Sci Med 41: 1705-1713.

17. Dreyer G, Medeiros Z, Netto MJ, Leal NC, Gonzaga de Castro L, Piessens WF (1999) Acute attacks in the extremities of persons living in an area endemic for Bancroftian filariasis: differentiation of two syndromes. Trans R Soc Trop Med Hyg 93: 413-417.

18. Dreyer G, Ottesen EA, Galdino E, Andrade L, Rocha A, Medeiros Z, Moura I, Casimiro I, Beliz F, Coutinho A (1992) Renal abnormalities in microfilaremic patients with Bancroftian filariasis. Am J Trop Med Hyg 46: 745-751.

19. Addiss DG, Dimock KA, Eberhard ML, Lammie PJ (1995) Clinical, parasitologic and immunologic observations of patients with hydrocele and elephantiasis in an area with endemic lymphatic filariasis. J Infect Dis 171: 755-758.

20. Dreyer G, Noroes J, Figueredo-Silva J, Piessens WF (2000) Pathogenesis of lymphatic disease in bancroftian filariasis: A clinical perspective. Parasitol Today 16: 544-548.

21. Ravindran B (2003) Aping Jane Goodall: Insights into human lymphatic filariasis. Trends Parasitol 19: 105-109.

22. Debrah AY, Mand S, Specht S, Marfo-Debrekyei Y, Batsa L, Pfarr K, Larbi J, Lawson B, Taylor M, Adjei O, Hoerauf A (2006) Doxycycline Reduces Plasma VEGF-C/sVEGFR-3 and Improves Pathology in Lymphatic Filariasis. PLoS Pathog 2: e92.

23. Witte MH, Bernas MJ, Martin CP, Witte CL (2001) Lymphangiogenesis and lymphangiodysplasia: From molecular to clinical lymphology. Microsc Res Tech 55: 122145.

24. Takahashi M, Yoshimoto T, Kubo H (2004) Molecular mechanisms of lymphangiogenesis. Int J Hematol 80: 29-34.

25. Ruocco V, Schwartz RA, Ruocco E (2002) Lymphoedema: An immunologically vulnerable site for development of neoplasms. J Am Acad Dermatol 47: 124-127. 
26. Saaristo A, Karkkainen MJ, Alitalo K (2002) Insights into the molecular pathogenesis and targeted treatment of lymphoedema. Ann N Y Acad Sci 979: 94-110.

27. Achen MG, Jeltsch M, Kukk E, Makinen T, Vitali A, Wilks AF, Alitalo K, Stacker SA (1998) Vascular endothelial growth factor D (VEGF-D) is a ligand for the tyrosine kinases VEGF receptor 2 (Flk1) and VEGF receptor 3 (Flt4). Proc Natl Acad Sci 95: 548-553.

28. Korpelainen EI, Alitalo K (1998) Signaling angiogenesis and lymphangiogenesis. Curr Opin Cell Biol 10: 159-164.

29. Ristimaki A, Narko K, Enholm B, Joukov V, Alitalo K (1998) Proinflammatory cytokines regulate expression of the lymphatic endothelial mitogen vascular endothelial growth factor-C. J Biol Chem 273: 8413-8418.

30. Taylor MJ, Bandi C, Hoerauf A (2005) Wolbachia bacterial endosymbionts of filarial nematodes. Adv Parasitol 60: 245284.

31. Raman U, Eswaran D, Narayanan RB, Jayaraman K, Kaliraj P (1999) Proinflammatory cytokines secreted by monocytes of filarial patients. Microbiol Immunol 43: 279-283.

32. Brattig NW, Rathjens U, Ernst M, Geisinger F, Renz A, Tischendorf FW (2000) Lipopolysaccharide-like molecules derived from Wolbachia endobacteria of the filaria Onchocerca volvulus are candidate mediators in the sequence of inflammatory and anti-inflammatory responses of human monocytes. Microbes Infect 2: 1147-1157.

33. Dickerson JW, Eberhard ML, Lammie PJ (1990) A technique for microfilarial detection in preserved blood using nuclepore filters. J Parasitol 76: 829-833.

34. Nuchprayoon S (2009) DNA-based diagnosis of lymphatic filariasis. Southeast Asian J Trop Med Public Health 40: 904913.

35. Williams SA, Laney SJ, Bierwert LA, Saunders LJ, Boakye DA, Fischer P, Goodman D, Helmy H, Hoti SL, Vasuki V, Lammie PJ, Plichart C, Ramzy RM, Ottesen EA (2002) Development and standardization of a rapid, PCR based method for the detection of Wuchereria bancroftian mosquitoes, for xenomonitoring the human prevalence of bancroftian filariasis. Ann Trop Med Parasitol 96: S41-S46.

36. Fischer P, Boakye D, Hamburger J (2003) Polymerase chain reaction-based detection of lymphatic filariasis. Med Microbiol Immunol 192: 3-7.

37. Amaral F, Dreyer G, Figueredo-Silva J, Noroes J, Cavalcanti A, Samico SC, Santos A, Coutinho A (1994) Live adult worms detected by ultrasonography in human Bancroftian filariasis. Am J Trop Med Hyg 50: 753-757.

38. Chaubal NG, Pradhan GM, Chaubal JN, Ramani SK (2003) Dance of Live Adult Filarial Worms Is a Reliable Sign of Scrotal Filarial Infection. J Ultrasound Med 22: 765-769.

39. Shyamkumar NK, Mehrotra S, Philip R, Taranath A, Nair S, Chacko NK (2004) Can we see microfilaria on ultrasound? A real-time ultrasound and wet smear demonstration of dancing microfilaria. J Urol 2: 1.

40. Dreyer G, Amaral F, Noroes J, Medeiros Z, Addiss D (1995) A new tool to assess the adulticidal efficacy in vivo of antifilarial drugs for Bancroftian filariasis. Trans R Soc Trop Med Hyg 89: 225-226.

41. Noroes J, Addiss D, Santos A, Medeiros Z, Coutinho A, Dreyer G (1996) Ultrasonographic evidence of abnormal lymphatic vessels in young men with Wuchereria bancrofti infection in the scrotal area. J Urol 156: 409-412.

42. Adejolu M, Sidhu PS (2011) The "Filarial Dance" Is Not Characteristic of Filariasis; Observations of "Dancing
Megasperm" on High-Resolution Sonography in Patients From Nonendemic Areas Mimicking the Filarial Dance and a Proposed Mechanism for This Phenomenon. Ultrasound Med 30: 1145-1150.

43. Rocha A, Addiss D, Ribeiro ME, Norões J, Baliza M, Medeiros Z, Dreyer G (1996) Evaluation of the Og4C3 ELISA in Wuchereria bancrofti infection: infected persons with undetectable or ultralow microfilarial densities. Trop Med Int Health 1: 859-864.

44. Debrah AY, Mand S, Marfo-Debrekyei Y, Batsa L, Pfarr K, Lawson B, Taylor M, Adjei O, Hoerauf A (2009) Reduction in Levels of Plasma Vascular Endothelial Growth Factor-A and Improvement in Hydrocele Patients by Targeting Endosymbiotic Wolbachia sp. in Wuchereria bancrofti with Doxycycline. Am J Trop Med Hyg 80: 956-963.

45. Dreyer G, Santos A, Norões J, Amaral F, Addiss D (1998) Ultrasonographic detection of living adult Wuchereria bancrofti using a 3.5-MHz transducer. Am J Trop Med Hyg 59: 399-403.

46. Gooding GAW, Leonhardt WC, Marshall G, Seltzer MA, Presti JC (1997) Cholesterol Crystals in Hydroceles: Sonographic Detection and Possible Significance. AJR 169: 527-529.

47. Dreyer G, Noroes J, Amaral F, Nen A, Medeiros Z, Coutinho A, Addiss D (1995) Direct assessment of the adulticidal efficacy of a single dose of ivermectin in bancroftian filariasis. Tran R Soc Trop Med Hyg 89: 441-443.

48. Plaisier AP, Cao WC, van Oortmarssen GJ, Habbema JD (1999) Efficacy of ivermectin in the treatment of Wuchereria Bancrofti infection: a model-based analysis of trial results. Parasitology 119: 385-394.

49. Richard-Lenoble D, Chandenier J, Gaxotte P (2003) Ivermectin and filariasis. Fundam Clin Pharmacol 17: 199203.

50. Dreyer G, Addiss D, Santos A, Figueredo-Silva, Noroes J (1998) Direct assessment in vivo of the efficacy of combined single-dose ivermectin and diethylcarbamazine against adult Wuchereria bancrofti. Trans R Soc Trop Med Hyg 92: 219.

51. Osei-Atweneboana MY, Awadzi K, Attah SK, Boakye DA, Gyapong JO, Prichard RK (2011) Phenotypic Evidence of Emerging Ivermectin Resistance in Onchocerca volvulus. PLoS Neg Trop Dis 5: e998.

52. Noroes J, Dreyer G, Santos A, Mendes VG, Medeiros Z, Addiss D (1997) Assessment of the efficacy of Diethylcarbamazine on adult Wuchereria bancrofti in vivo. Trans R Soc Trop Med Hyg 91: 78-81.

53. Ottesen EA, Ismail MM, Horton J (1999) The role of albendazole in programmes to eliminate lymphatic filariasis. Parasitol Today 15: 382-386.

54. Kshirsagar NA, Gogtay NJ, Garg BS, Deshmukh PR, Rajgor DD, Kadam VS, Kirodian BG, Ingole NS, Mehendale AM, Fleckenstein L, Karbwang J, Lazdins-Helds JK (2004) Safety, tolerability, efficacy and plasma concentrations of diethylcarbamazine and albendazole co-administration in a field study in an area endemic for lymphatic filariasis in India. Trans R Soc Trop Med Hyg 98: 205-217.

55. Fan PC (1990) Eradication of bancroftian filariasis by diethylcarbamazine-medicated common salt on Little Kinmen (Liehyu District), Kinmen (Quemoy) Islands, Republic of China. Ann Trop Med Parasitol 84: 25-33.

56. Meyrowitsch DW, Simonsen PE, Makunde WH (1996) Mass diethylcarbamazine chemotherapy for control of bancroftianfilariasis through community participation: 
comparative efficacy of a low monthly dose and medicated salt. Trans R Soc Trop Med Hyg 90: 74-79.

57. Esterre P, Plichart C, Sechan Y, Nguyen NL (2001) The impact of 34 years of massive DEC chemotherapy on Wuchereria bancrofti infection and transmission: the Maupiti cohort. Trop Med Int Health 6: 190.

58. Freeman AR, Lammie PJ, Houston R, LaPointe MD, Streit TG, Jooste PL, Brissau JM, Lafontant JG, Addiss DG (2001) A community based trial for the control of lymphatic filariasis and iodine deficiency using salt fortified with diethylcarbamazine and iodine. Am J Trop Med Hyg 65: 865871.

59. Bockarie MJ, Tisch DJ, Kastens W, Alexander ND, Dimber Z, Bockarie F, Ibam E, Alpers MP, Kazura JW (2002) Mass treatment to eliminate filariasis in Papua New Guinea. New Eng J Med 347: 1841-1848.

60. Kyelem D, Sanou S, Boatin B, Medlock J, Coulibaly S, Molyneux DH (2003) Impact of long-term ivermectin (Mectizan) on Wuchereria bancrofti and Mansonella perstans infections in Burkina Faso: strategic and policy implications. Ann Trop Med Parasitol 97: 827-838.

61. Simonsen PE, Meyrowitsch DW, Mukoko DA, Pedersen EM, Malecela-Lazaro MN, Rwegoshora RT, Ouma JH, Masese N, Jaoko WG, Michael E (2004) The effect of repeated halfyearly diethylcarbamazine mass treatment on Wuchereria bancrofti infection and transmission in two East African communities with different levels of endemicity. A J Trop Med Hyg 70: 63-71.

62. Liang JL, King JD, Ichimori K, Handzel T, Pa'au M, Lammie PJ (2008) Impact of five annual rounds of mass drug administration with diethylcarbamazine and albendazoleon Wuchereria bancrofti infection in American Samoa. Am J Trop Med Hyg 78: 924-928.
63. Nutman TB (2001) Blood-borne Filarial Infections: Wuchereria bancrofti, Brugia malayi, Brugia timori, Loa loa, Mansonella perstans and Mansonella ozzardi. In Gillespie S, Pearson RD, editors. Principles and Practice of Clinical Parasitology. West Sussex: John Wiley and Sons Ltd. 457478.

64. Hoerauf A, Nissen-Pähle K, Schmetz C, Henkle-Dührsen K, Blaxter ML, Büttner DW, Gallin MY, Al-Qaoud KM, Lucius R, Fleischer B (1998) Tetracycline therapy targets intracellular bacteria in the filarial nematode Litomosoides sigmodontis and results in filarial infertility. J Clin Invest 103: 11-18.

65. Hoerauf A, Mand S, Fischer K, Kruppa T, Marfo-Debrekyei Y, Debrah AY, Pfarr KM, Adjei O, Büttner DW (2003) Doxycycline as a novel strategy against bancroftian filariasisdepletion of Wolbachia endosymbionts from Wuchereria bancrofti and stop of microfilaria production. Med Microbiol Immunol 192: 211-216.

66. Hoerauf A (2008) Filariasis: new drugs and new opportunities for lymphatic filariasis and onchocerciasis. Cur Opin Infect Dis 21: 673-681.

\section{Corresponding author}

Kenneth Bentum Otabil

Lecturer/Medical Research Scientist

Department of Community Medicine and Health

Anglican University College of Technology

P.O Box 78 Nkoranza, BA, Ghana, West Africa

Phone: +233209164671

Email: ekowbentum@yahoo.com

Conflict of interests: No conflict of interests is declared. 